University of Wollongong

Research Online

Australian Institute for Innovative Materials -

Papers

Australian Institute for Innovative Materials

$1-1-2018$

\title{
Molecular-Scale Functionality on Graphene To Unlock the Energy Capabilities of Metal Hydrides for High-Capacity Lithium-Ion Batteries
}

\author{
Guanglin Xia \\ University of Wollongong, Fudan University, guanglin@uow.edu.au \\ Baoping Zhang \\ Fudan University \\ Xiaowei Chen \\ Jimei University, chenx@nju.edu.cn \\ Dalin Sun \\ Fudan University \\ Zaiping Guo \\ University of Wollongong, zguo@uow.edu.au
}

See next page for additional authors

Follow this and additional works at: https://ro.uow.edu.au/aiimpapers

Part of the Engineering Commons, and the Physical Sciences and Mathematics Commons

Research Online is the open access institutional repository for the University of Wollongong. For further information contact the UOW Library: research-pubs@uow.edu.au 


\title{
Molecular-Scale Functionality on Graphene To Unlock the Energy Capabilities of Metal Hydrides for High-Capacity Lithium-Ion Batteries
}

\author{
Abstract \\ Metal hydrides have attracted great intentions as anodes for lithium-ion batteries (LIBs) due to their \\ extraordinary theoretical capacity. It is an unsolved challenge, however, to achieve high capacity with \\ stable cyclability, owing to their insulating property and large volume expansion upon lithium storage. \\ Here, we introduce self-initiated polymerization to realize molecular-scale functionality of metal hydrides \\ with conductive polymer, that is, polythiophene (PTh), on graphene, leading to the formation of \\ $\mathrm{MgH} 2 @ \mathrm{PTh}$ core-shell nanoparticles on graphene. The nanoscale characteristics of $\mathrm{MgH} 2$ not only \\ relieve the induced stress upon volume changes but also allow fast diffusivity and high reactivity for Li-ion \\ transport. More importantly, the conformal coating of ultrathin PTh membrane can effectively suppress \\ the detrimental reactions between $\mathrm{MgH} 2$ and electrolyte, provide enhanced performance with facile \\ electron and $\mathrm{Li}+$ transport, and preserve its structural integrity, attributed to the strong molecular \\ interaction between PTh and $\mathrm{MgH} 2$ as well as its various products during electrochemical reactions. With \\ this structure, a high reversible specific capacity of $1311 \mathrm{mAh} \mathrm{g-1}$ at $100 \mathrm{~mA} \mathrm{~g}-1$, excellent rate \\ performance of $1025 \mathrm{mAh} \mathrm{g}-1$ at $2000 \mathrm{~mA} \mathrm{~g}-1$, and a capacity retention of $84.5 \%$ at $2000 \mathrm{~mA} \mathrm{~g}-1$ after \\ 500 cycles are observed for MgH2@PTh nanoparticles as anode for LIBs.

\section{Disciplines} \\ Engineering | Physical Sciences and Mathematics

\section{Publication Details} \\ Xia, G., Zhang, B., Chen, X., Sun, D., Guo, Z., Liang, F., Zou, W., Yang, Z. \& Yu, X. (2018). Molecular-Scale \\ Functionality on Graphene To Unlock the Energy Capabilities of Metal Hydrides for High-Capacity Lithium- \\ Ion Batteries. Acs Nano, 12 (8), 8177-8186.

\section{Authors} \\ Guanglin Xia, Baoping Zhang, Xiaowei Chen, Dalin Sun, Zaiping Guo, Fuxin Liang, Weidong Zou, \\ Zhenzhong Yang, and Xuebin Yu
}




\section{Molecular-Scale Functionality on Graphene to}

\section{Unlock the Energy Capabilities of Metal Hydrides}

\section{for High-Capacity Lithium-Ion Batteries}

Guanglin Xia, ${ }^{\dagger,, \#}$ Baoping Zhang, ${ }^{\dagger, \#}$ Xiaowei Chen, ${ }^{\S}$ Dalin Sun,${ }^{\dagger}$ Zaiping Guo, ${ }^{\ddagger}$ Fuxin Liang,

Weidong Zou, ${ }^{\S}$ Zhenzhong Yang, ," and Xuebin $\mathrm{Yu}^{*}{ }^{* \dagger}$

${ }^{\dagger}$ Department of Materials Science, Fudan University, Shanghai 200433, China

Institute for Superconducting and Electronic Materials, University of Wollongong, North Wollongong, NSW 2522, Australia

"State Key Laboratory of Polymer Physics and Chemistry, Institute of Chemistry, Chinese Academy of Sciences, Beijing 100190, China

${ }^{\S}$ Department of Physics, Jimei University, Xiamen 361021, China

KEYWORDS: lithium-ion batteries, metal hydride, magnesium hydride, graphene, self-assembly 
ABSTRACT: Metal hydrides have attracted great intentions as anodes for lithium-ion batteries (LIBs) due to their extraordinary theoretical capacity. It is an unsolved challenge, however, to achieve high capacity with stable cyclability, owing to their insulating property and large volume expansion upon lithium storage. Here, we introduce self-initiated polymerization to realize molecular-scale functionality of metal hydrides with conductive polymer, i.e., polythiophene (PTh), on graphene, leading to the formation of $\mathrm{MgH}_{2} @ \mathrm{PTh}$ core-shell nanoparticles on graphene. The nanoscale characteristics of $\mathrm{MgH}_{2}$ not only relieve the induced stress upon volume changes, but also allow fast diffusivity and high reactivity for Li-ion transport. More importantly, the conformal coating of ultrathin PTh membrane can effectively suppress the detrimental reactions between $\mathrm{MgH}_{2}$ and electrolyte, provide enhanced performance with facile electron and $\mathrm{Li}^{+}$ transport, and preserve its structural integrity, attributed to the strong molecular interaction between PTh and $\mathrm{MgH}_{2}$, as well as its various products during electrochemical reactions. With this structure, a high reversible specific capacity of $1311 \mathrm{mAh} \mathrm{g}^{-1}$ at $100 \mathrm{~mA} \mathrm{~g}^{-1}$, excellent rate performance of $1025 \mathrm{mAh} \mathrm{g}^{-1}$ at $2000 \mathrm{~mA} \mathrm{~g}^{-1}$, and a capacity retention of $84.5 \%$ at $2000 \mathrm{~mA} \mathrm{~g}^{-1}$ after 500 cycles are observed for $\mathrm{MgH}_{2} @ \mathrm{PTh}$ nanoparticles as anode for LIBs. 
Rechargeable lithium-ion batteries (LIBs) are one of the predominant power sources for applications in the portable electronics market and are believed to be promising candidates for electrical vehicle and grid-scale energy storage due to their high energy density, high voltage, and environmental friendliness. ${ }^{1-5}$ The most common commercial graphite anode materials, however, exhibit a relatively low theoretical specific capacity of $372 \mathrm{mAh} \mathrm{g}^{-1}$. In order to meet the evergrowing energy and power demands of electrical devices, considerable research efforts have been devoted to the development of advanced electrode materials with high energy density, power density, and long cycle life at low cost. ${ }^{6-8}$ Accordingly, the use of metal hydrides has been proposed by Oumellal et al. in 2008 and further developed as very high capacity materials for LIBs. ${ }^{9,}{ }^{10}$ It has been experimentally demonstrated that several metal hydrides could react with lithium during the last decade based on the following reaction: $\mathrm{MH}_{x}+x \mathrm{Li}^{+}+x \mathrm{e}^{-} \rightleftharpoons \mathrm{M}+x \mathrm{LiH} .{ }^{9}{ }^{10}$ Among them, magnesium hydride $\left(\mathrm{MgH}_{2}\right)$ in particular is attracting extensive attention in view of its high theoretical capacity of $2038 \mathrm{mAh} \mathrm{g}^{-1}$, owing to the much lower molecular weights of magnesium and hydrogen, and the safe potential window of $0.1-0.5 \mathrm{~V}$ versus $\mathrm{Li}^{+} / \mathrm{Li}^{0}$ with the low cost and high natural abundance ( $2.5 \%$ of Earth's surface composition, and virtually in unlimited amounts in sea water). ${ }^{9}$ It has been found that a full discharge capacity of $\mathrm{MgH}_{2}$ could be achieved in the first cycle and a high reversible capacity of $1480 \mathrm{mAh} \mathrm{g}^{-1}$ is obtained in liquid electrolyte at room temperature, which is 4 times that of traditional Li/graphite electrodes at a suitable potential $(0.5$ $\mathrm{V} v s . \mathrm{Li}^{+} / \mathrm{Li}^{0}$ ) for a negative electrode. ${ }^{9}$ Additionally, $\mathrm{MgH}_{2}$ as anode material displays the lowest value of polarization $\left(0.2 \mathrm{~V} v s . \mathrm{Li}^{+} / \mathrm{Li}^{0}\right)$ ever reported compared to all other conversion electrodes due to the facile transportation of hydrogen, which could effectively reduce the self-heating effect during cycling and the risk of thermal runaway. ${ }^{9-11}$ Unfortunately, the practical application of $\mathrm{MgH}_{2}$ as anode is significantly hindered by the rapid capacity fading during cycling (a capacity of 
less than $200 \mathrm{~mA} \mathrm{~h} \mathrm{~g}^{-1}$ after only 10 complete cycles), poor rate capability, and low Coulombic efficiency, which is attributed to its intrinsically low electronic conductivity, aggregation, and loss of electrical contact with the current collector induced by large volume changes and pulverization occurring during the lithiation-delithiation cycling. ${ }^{12,13}$

In the case of the electrode materials that experience large volume changes during charge/discharge in liquid electrolyte at room temperature, effective mitigation of the negative impact of the enormous volumetric changes on the electrochemical performance is the key challenge to enable the practical application of this class of alloying or conversion reaction electrode materials. ${ }^{14}$ Recently, extensive research on conversion reaction electrodes has demonstrated that decreasing particle size or electrode nanostructuring is a common strategy to enhance their rate capability by effectively shortening the $\mathrm{Li}^{+}$diffusion distance and enabling the electrode to withstand high volumetric strains associated with repeated lithium insertion/extraction. ${ }^{15}$ Building core-shell nanostructures by integrating electroactive materials with conducting additives, such as carbon or conductive polymer, as the shells has also been reported to improve their electrical conductivity and prevent agglomeration, leading to enhanced electrochemical performance of the active materials. ${ }^{16-23}$ For example, Wu and coworkers reported the formation of $\mathrm{CuO} @$ carbon-nitride core-shell nanocable array, which could benefit the reversible accommodation of the volume change of the $\mathrm{CuO}$ active materials, leading to a reversible capacity as high as $669 \mathrm{mAh} \mathrm{g}^{-1}$ after 200 cycles. ${ }^{14}$ The core-shell assembly of graphene around $\mathrm{Fe}_{2} \mathrm{O}_{3}$ could achieve a high reversible capacity, significantly enhanced cycling stability, and excellent rate capacity of $\mathrm{Fe}_{2} \mathrm{O}_{3}$ compared with pristine $\mathrm{Fe}_{2} \mathrm{O}_{3}$, which is mainly attributed to the important role of graphene shell in preventing aggregation, buffering the volume change, maintaining the integrity of the active materials, and improving the conductivity of the electrode. ${ }^{24}$ 
In addition, Zhu and co-workers reported that building the $\mathrm{Fe}_{3} \mathrm{O}_{4} @$ polypyrrole core-shell structures could effectively facilitate the rapid ion/electron transportation for electrochemical reaction, leading to superior lithium storage performance ${ }^{25}$ More recently, uniform distribution of $\mathrm{Sn}$ in the core-shell $\mathrm{TiO}_{2}$ - $\mathrm{Sn} @$ carbon nanofibers has been demonstrated as an effective strategy to not only buffer the volume variation of $\mathrm{Sn}$ and prevent the aggregation and pulverization during cycling discharge-charge process, but also improve the electronic conductivity of the electrode. ${ }^{26}$ Unfortunately, although a significant improvement has been demonstrated for those metal-oxide (nitride and/or sulfide)-based anode materials, based on combining the advantages of these two strategies, the synthesis of anodes with stable nanostructures is still challenging due to the lack of rational design on the molecular level. In particular, the practical performance of $\mathrm{MgH}_{2}$ anode material has fallen far short of the theoretical promise, and the related development has been rather slow because of the limited application of existing anode technologies in this field. A recent study in our group has demonstrated that anchoring $\mathrm{MgH}_{2}$ nanoparticles on graphene, combined with poly(methyl methacrylate) (PMMA) as the binder, could effectively improve the reversibility of $\mathrm{MgH}_{2}$-based anodes. ${ }^{27}$ Only a reversible capacity of $395 \mathrm{mAh} \mathrm{g}^{-1}$, however, could be maintained at $2000 \mathrm{~mA} \mathrm{~g}^{-1}$ after 1000 cycles. Therefore, in order to satisfy the continuing demand for advanced LIBs with higher capacity, the energy capacity of $\mathrm{MgH}_{2}$-based anodes needs to be urgently unlocked to develop high-performance LIBs via the uniform and rational integration of both nanostructure engineering and hybridization based on molecular level.

In this study, to achieve a high reversible capacity with stable cyclability, we have fabricated an anode consisting of graphene-supported $\mathrm{MgH}_{2} @$ polythiophene (PTh) core-shell nanoparticles (G/MgH $\mathrm{Mg}_{2} @ \mathrm{PTh}$ ), using a self-initiated polymerization induced by $\mathrm{Mg}$ nanocrystals (NCs) to unlock the energy capabilities of metal hydrides. First, graphene, a monolayer of carbon atoms 
arranged in a honeycomb network, exhibits many amazing properties, such as high electrical conductivity, high surface area, and excellent chemical stability, which makes it a good carbon platform to improve the electrochemical properties of $\mathrm{MgH}_{2}$ anodes. ${ }^{28,29}$ Taking advantage of the Mg-induced selective and self-limiting polymerization of thiophene and the favorable molecular adsorption of thiophene on Mg nanocrystals (NCs), $\mathrm{MgH}_{2} @ \mathrm{PT}$ P core-shell nanoparticles (NPs) uniformly distributed on graphene are built after the complete hydrogenation of Mg NCs, leading to molecular-scale control of the functionality of electroactive $\mathrm{MgH}_{2} \mathrm{NCs}$ with a self-induced electronically-conductive PTh coating. This designed structure is ideal for homogeneous coating of $\mathrm{MgH}_{2} \mathrm{NCs}$ and inhibiting the aggregation of $\mathrm{MgH}_{2} \mathrm{NCs}$, leading to long-term stable cycling performance with high capacity. Furthermore, the intimate and homogeneous contact between $\mathrm{MgH}_{2} \mathrm{NCs}$ and electron-conducting PTh nanofilms, as well as cross-linked graphene, offers fast transport pathways for electrons and $\mathrm{Li}^{+}$diffusion, effectively absorbing the mechanical stress induced by volume expansion and efficiently preventing the detrimental reactions between $\mathrm{MgH}_{2}$ and electrolyte. Consequently, a LIB anode with this purposely optimized nanostructure was able to deliver the high reversible capacity of $1311 \mathrm{mAh} \mathrm{g}^{-1}$, based on the mass of $\mathrm{MgH}_{2}$ at $100 \mathrm{~mA} \mathrm{~g}^{-}$ ${ }^{1}$, and a significantly enhanced reversible capacity of $884 \mathrm{mAh} \mathrm{g}^{-1}$ at a high current density of 2000 $\mathrm{mA} \mathrm{g}^{-1}$ after 500 cycles.

\section{RESULTS AND DISCUSSION}

Figure 1a illustrates the detailed synthesis procedure for $\mathrm{G} / \mathrm{MgH}_{2} @ \mathrm{PTh}$. First, $\mathrm{MgH}_{2} \mathrm{NCs}$ homogeneously distributed on graphene $\left(\mathrm{G} / \mathrm{MgH}_{2} \mathrm{NCs}\right)$ were facilely synthesized according to the hydrogenation-induced self-assembly of dibutyl magnesium on graphene, and they were then transformed into graphene-supported Mg NCs via simple thermal annealing as the functional nanoreactor. ${ }^{30}$ Subsequently, a Mg-induced reductive transformation based on the following 
reaction: $n \mathrm{Mg}+n \mathrm{C}_{4} \mathrm{H}_{2} \mathrm{SBr}_{2} \rightarrow n \mathrm{MgBr}_{2}+\mathrm{PTh}$ resulted in a homogeneous and selective coating of PTh on the Mg NCs to form Mg@PTh core-shell nanoparticles (NPs) distributed on graphene (G/Mg@PTh). ${ }^{31}$ Furthermore, in order to investigate the molecular interactions during the selfinitiated polymerization, density functional theory (DFT) calculations were conducted. It was calculated that, under the most stable geometrical configurations, the binding energy between $\mathrm{C}_{4} \mathrm{H}_{2} \mathrm{SBr}_{2}$ and $\mathrm{Mg}$ was $0.55 \mathrm{eV}$ (Figure 1b), indicating the favorable adsorption of the thiophene monomer on the surface of $\mathrm{Mg} \mathrm{NCs} \mathrm{in} \mathrm{the} \mathrm{initial} \mathrm{stage} \mathrm{of} \mathrm{polymerization.} \mathrm{A} \mathrm{stronger} \mathrm{molecular}$ interaction between $\mathrm{C}_{4} \mathrm{H}_{2} \mathrm{SMgBr}$, which is the intermediate product of the reaction, and $\mathrm{Mg} \mathrm{NCs}$ is observed as evidenced by the increase in binding energy to $2.68 \mathrm{eV}$, and there is even a large transfer of charge from $\mathrm{Mg}$ to $\mathrm{C}_{4} \mathrm{H}_{2} \mathrm{SMgBr}$ due to the low electronegativity of $\mathrm{Mg}$ (Figure 1c). This finding indicates that, by virtue of the favorable molecular interaction between $\mathrm{Mg} \mathrm{NCs}$ and $\mathrm{C}_{4} \mathrm{H}_{2} \mathrm{SBr}_{2}$ and/or $\mathrm{C}_{4} \mathrm{H}_{2} \mathrm{SMgBr}$, the ultrathin PTh membrane synthesized in-situ could be uniformly coated on the surfaces of the individual Mg NCs. Finally, G/MgH $\mathrm{Mg}_{2}$ PTh was obtained through hydrogenation of the Mg NCs in $\mathrm{G} / \mathrm{Mg} @ \mathrm{PTh}$.

The morphology of the as-synthesized products was subsequently investigated by field-emission scanning electron microscopy (FE-SEM) and transmission electron microscopy (TEM). Figure 2a shows the formation of homogeneous $\mathrm{MgH}_{2} \mathrm{NCs}$ with an average particle size of around $13.8 \mathrm{~nm}$ uniformly anchored on graphene after the hydrogenation-induced self-assembly process (Figure S1), which offers facile pathways for the uniform adsorption of thiophene monomer and the subsequent homogeneous functionality of $\mathrm{MgH}_{2} \mathrm{NCs}$ with PTh films. Meanwhile, the flexible graphene provides stable structural support for the following chemical reaction. X-ray powder diffraction (XRD) measurements demonstrated the formation of cubic $\mathrm{MgH}_{2}$ (Figure $\mathrm{S} 2$ in the Supporting Information), and the X-ray photoelectron spectroscopy (XPS) (Figure S3) results also 
confirmed the presence of characteristic $\mathrm{Mg}-\mathrm{H}$ bonds belonging to $\mathrm{MgH}_{2}$. After the dehydrogenation process via thermal treatment at $300{ }^{\circ} \mathrm{C}$, the homogeneous distribution of $\mathrm{Mg}$ NCs is well preserved with no visible aggregation (Figure S4), and the formation of Mg NCs could be clearly supported by XRD patterns (Figure S2). It was further adopted as the functional and robust nanoreactor to realize the self-initiated polymerization of thiophene monomer into PTh on the surfaces of the Mg NCs. The completion of the polymerization reaction could be attested by the formation of $\mathrm{MgBr}_{2}$ in the product of the solution after the removal of solvent and $\mathrm{G} / \mathrm{Mg} @ \mathrm{PTh}$ (Figure S5), and two typical Raman scattering peaks at 671 and $1455 \mathrm{~cm}^{-1}$, corresponding to the $\mathrm{C}-\mathrm{S}$ stretching bands and the symmetric stretching vibrations of the aromatic $\mathrm{C}=\mathrm{C}$ ring bond of PTh, respectively, are present in G/Mg@PTh (Figure S6), which directly demonstrates the successful formation of PTh in the G/Mg@PTh composite. ${ }^{32}$ Furthermore, due to the presence of graphene as structural support, the homogeneous distribution of $\mathrm{Mg} \mathrm{NCs}$ on graphene is well maintained without obvious agglomeration or growth, as confirmed by representative FE-SEM and TEM images of G/Mg@PTh (Figure 2b, c), and the uniform coating of PTh can be clearly observed attributed to both the selective and self-limiting reaction and the favorable adsorption between Mg NCs and the monomer.

After the hydrogenation of the Mg NCs in G/Mg@PTh into $\mathrm{MgH}_{2} \mathrm{NCs}$, XRD patterns confirm the synthesis of $\mathrm{MgH}_{2}$ with the complete absence of the precursor Mg NCs (Figure S2), while the characteristic peaks of PTh remain unchanged in the Raman spectrum of G/MgH $@$ PTh (Figure S7), validating the complete transformation of $\mathrm{MgH}_{2}$ from $\mathrm{Mg} \mathrm{NCs}$ and the good preservation of PTh during the hydrogenation process. More importantly, the $\mathrm{G} / \mathrm{MgH}_{2} @ \mathrm{PTh}$ perfectly maintains the high monodispersivity of the $\mathrm{MgH}_{2} \mathrm{NCs}$ on graphene, with the entire surface uniformly covered by ultrathin PTh membrane, as illustrated in the SEM (Figures 2d), TEM (Figure 2e), and 
STEM (Figure 2f) images, and this could be further supported by the high-resolution SEM images obtained at different multiple spots (Figure S8). The sandwich-like morphology homogeneously embedded with $\mathrm{MgH}_{2} @$ PTh core-shell NPs ensures good electrical connection between the electroactive particles. A high-resolution TEM (HRTEM) image reveals the uniform core-shell structure of $\mathrm{MgH}_{2} @ \mathrm{PTh}$ NPs uniformly distributed on a graphene layer (Figure 2g), in which the entire surface of the $\mathrm{MgH}_{2} \mathrm{NCs}$ is uniformly covered with a continuous amorphous layer of PTh. By comparison, only a clear crystal boundary is observed for the $\mathrm{MgH}_{2} \mathrm{NCs}$ in $\mathrm{G} / \mathrm{MgH}_{2} \mathrm{NC}$ (Figure S9). In addition, compared to bare $\mathrm{G} / \mathrm{MgH}_{2} \mathrm{NC}$, the signals in the dark-field TEM images (Figure S10) of G/MgH$@$ @PTh become blurrier due to the covering of $\mathrm{MgH}_{2} \mathrm{NCs}$ with PTh membrane. In order to gain a clear observation of the homogeneous coating of PTh on $\mathrm{MgH}_{2} \mathrm{NCs}$, G/MgH$@ @$ PTh was soaked in $\mathrm{HCl}$ solution to etch away the inner $\mathrm{MgH}_{2} \mathrm{NCs}$. The TEM images (Figure S11) obviously disclose that the conformal shape of the PTh membrane with an ultrathin thickness of $\sim 2 \mathrm{~nm}$, and its amorphous nature is well maintained after strong sonication. As a result, the average particle size of $\mathrm{MgH}_{2} \mathrm{NCs}$ in $\mathrm{G} / \mathrm{MgH}_{2} @ \mathrm{PTh}$ increases from $13.8 \mathrm{~nm}$ to 15.6 $\mathrm{nm}$ after the formation of $\mathrm{PTh}$ membrane on the surface of $\mathrm{MgH}_{2} \mathrm{NCs}$ (Figure S1), indicating the homogeneous coating of PTh membrane. The PTh membrane is uniformly distributed on the graphene with only partial hollow nanoparticles depressed into it due to the disappearance of the supporting structure of inner $\mathrm{MgH}_{2} \mathrm{NCs}$. This also demonstrates the satisfactory resilience of PTh membrane under mechanical forces, which makes it well suited to accommodate the volume expansion of metal hydrides during repeated lithiation/delithiation processes. The intimate interface interaction between $\mathrm{PTh}$, which is an electron-conducting polymer, and $\mathrm{MgH}_{2}$ in the core-shell nanostructure could further effectively enhance the electrical conductivity from $\mathrm{MgH}_{2}$ to the current collector and meanwhile, alleviate the volume changes from lithium 
extraction/insertion during cycling. Interestingly, it is found that the binding energy between the PTh membrane and the graphene obtained from DFT calculations reaches as high as $1.42 \mathrm{eV}$ (Figure 1d), while the binding energy of the $\mathrm{MgH}_{2}$-graphene system is only $0.3 \mathrm{eV}$ (Figure $\mathrm{S} 12$ ), suggesting the much more favorable adsorption between PTh and graphene. Therefore, the homogeneous functionality of $\mathrm{MgH}_{2}$ with $\mathrm{PTh}$ membrane could further facilitate the robust anchoring of monodisperse $\mathrm{MgH}_{2}$ on graphene through the strong molecular interaction between PTh and graphene, thereby preventing aggregation during the lithiation and delithiation over the course of long-term cycling. The porous structure of G/MgH $@$ @PTh resulting from the assembly of graphene and $\mathrm{MgH}_{2} @ \mathrm{PTh}$ NPs certified by SEM and TEM images was further investigated by Nitrogen sorption isotherms, exhibiting typical type-IV behavior with an obvious hysteresis loop between relative pressures $\left(P / P_{0}\right)$ of 0.5 and 1.0 , which is the characteristic of the presence of mesopores (Figure S13a). The Brunauer-Emmett-Teller (BET) surface area of G/MgH $@$ PTh is calculated to be as high as $153 \mathrm{~m}^{2} \mathrm{~g}^{-1}$, with a wide pore size distribution from 3 to $20 \mathrm{~nm}$ (Figure S13b), validating its mesoporous structure. The abundant porosity with large surface area is beneficial for accelerating the mass diffusion of electrolyte and alleviating the volume changes of $\mathrm{MgH}_{2}$ anode during cycling charge/discharge processes, leading to improved electrochemical performance. Furthermore, the elemental line-scan profiles on the graphene-supported $\mathrm{MgH}_{2} @$ PTh core-shell NPs show single Gaussian distributions across the particle for the elements $\mathrm{C}, \mathrm{Mg}$, and $\mathrm{S}$, confirming that the conductive PTh membrane is uniformly coated on the surfaces of the $\mathrm{MgH}_{2}$ NCs. The energy dispersive X-ray (EDX) spectrum of G/MgH $@$ PTh also demonstrates the presence of the elements $\mathrm{C}, \mathrm{Mg}$, and $\mathrm{S}$ (Figure S14), and the corresponding elemental mapping (Figure 2i) authenticates the homogeneous distribution of $\mathrm{Mg}, \mathrm{C}$, and $\mathrm{S}$ in the composite, providing further evidence for the uniform functionality of $\mathrm{MgH}_{2} \mathrm{NCs}$ with $\mathrm{PTh}$ 
membrane. Moreover, the HRTEM image of G/MgH$@ \mathrm{PTh}$ (Figure 2g) displays clear lattice fringes with a $d$-spacing of $\sim 0.23 \mathrm{~nm}$, corresponding to the (200) lattice planes of $\mathrm{MgH}_{2}$, which is in good agreement with the XRD results.

Further evidence for the formation of $\mathrm{MgH}_{2} \mathrm{NCs}$ in the as-prepared composite is obtained from the Raman spectra of G/MgH$@ \mathrm{MgTh}_{2}$ and G/MgH $\mathrm{NCs}$ (Figure S7), which unveil the characteristic Raman-active Eg phonons of $\mathrm{MgH}_{2}$ at $952 \mathrm{~cm}^{-1} .{ }^{33}$ Additionally, two broad peaks at round 1350 and $1593 \mathrm{~cm}^{-1}$ are ascribed to the $\mathrm{D}$ and $\mathrm{G}$ bands of graphene, corresponding to $s p^{3}$-type disordered carbon atoms in the hexagonal graphite network and the in-plane vibrational mode of $s p^{2}$-bonded carbon atoms, respectively. The intensity of the D band is higher than that of the G band, which indicates a more disordered stack of graphene in the hybrid, favoring the diffusion of $\mathrm{Li}$ ions. ${ }^{34} \mathrm{In}$ addition, the chemical composition of $\mathrm{G} / \mathrm{MgH}_{2} @ \mathrm{PTh}$ was investigated by X-ray photoelectron spectroscopy (XPS), which demonstrated the presence of $\mathrm{C}, \mathrm{Mg}$, and $\mathrm{S}$ in the composite (Figure S15a), validating the high purity of the as-prepared sample. Moreover, the high-resolution $\mathrm{Mg} 2 \mathrm{p}$ spectrum and the $S 2 p$ XPS spectrum (Figures $S 15 b, c)$ ), composed of $S 2 p_{3 / 2}$ and $S 2 p_{1 / 2}$ peaks attributed to the sulfur in PTh membrane, provide additional evidence for the existence of $\mathrm{MgH}_{2}$ and PTh in G/MgH $\mathrm{Mg}_{2} @ \mathrm{PTh}$. All these results demonstrate that the macular-scale functionality of $\mathrm{MgH}_{2}$ with conductive PTh nanofilms on graphene has been successfully achieved by adopting the self-initiated polymerization. In order to verify the amount of $\mathrm{MgH}_{2}$ in $\mathrm{G} / \mathrm{MgH}_{2} @ \mathrm{PTh}$, the hydrogen capacity absorbed by G/Mg@PTh for the conversion to G/MgH $\mathrm{Mg}_{2} @ \mathrm{PTh}$ was detected and calculated to be $3.92 \mathrm{wt} . \%$ (Figure S16) and no hydrogenation reaction was observed for G/PTh (Figure S16) and pure PTh under the identical condition (Figure S17). It corresponds to $51.6 \mathrm{wt} \%$ of $\mathrm{MgH}_{2} \mathrm{NCs}$ in $\mathrm{G} / \mathrm{MgH}_{2} @ \mathrm{PTh}$ taking into account the complete hydrogenation of $\mathrm{Mg}$ 
into $\mathrm{MgH}_{2}$, as reflected by the XRD results, which agrees well with the results obtained from the hydrolysis reaction (Figure S18).

The battery performance of $\mathrm{G} / \mathrm{MgH}_{2} @ \mathrm{PTh}$ as electrode material was first evaluated by galvanostatic charge-discharge cycling measurements at a constant current density of $100 \mathrm{~mA} \mathrm{~g}^{-1}$. The initial discharge profile consists of a plateau at $\sim 0.9 \mathrm{~V}$, which could be attributed to the formation of solid-electrolyte interphase (SEI) films (Figure S19). A slight plateau between 0.26 and $0.04 \mathrm{~V}$ corresponds to the reduction of $\mathrm{MgH}_{2}$ to $\mathrm{Mg}$, accompanied by the formation of $\mathrm{LiH}$. The XRD patterns of G/MgH $\mathrm{MgTh}_{2}$ (Figure 3b) elucidate the formation of LiH and Mg with the disappearance of $\mathrm{MgH}_{2}$ when the electrode was discharged to $0.04 \mathrm{~V}$, indicating the completion of the conversion reaction in this stage. ${ }^{9}$ Additionally, the plateau that occurs below $0.04 \mathrm{~V}$, approaching the cut-off potential, is attributed to the alloying of $\mathrm{Mg}$ with $\mathrm{Li}$ according to the XRD results, which validates the presence of hep-type $\mathrm{Li}-\mathrm{Mg}$ solid solution alloys (hcp-type $\mathrm{Li}_{\mathrm{x}} \mathrm{Mg}$, (x $\leq 0.15)$ ) coupled with the absence of $\mathrm{Mg} .{ }^{9}$ After full lithiation, the $d$-spacings of the crystalline nano-domains dispersed on graphene (Figure 3c) were measured to be 0.20 and $0.28 \mathrm{~nm}$, corresponding to the (200) planes of $\mathrm{LiH}$ and the (100) planes of hep-type $\mathrm{Li}_{\mathrm{x}} \mathrm{Mg}(\mathrm{x} \leq 0.15)$, respectively, in good agreement with the XRD results. In the first charge process, two plateaus located at $0.22 \mathrm{~V}$ and $0.59 \mathrm{~V}$ are observed, corresponding to the de-alloying of hep-type $\mathrm{Li} \mathrm{x}_{\mathrm{x}} \mathrm{Mg}$ alloys and the oxidation of $\mathrm{Mg}$ into $\mathrm{MgH}_{2}$, respectively. This could be supported by the presence of $\mathrm{MgH}_{2}$ accompanied with the disappearance of $\mathrm{LiH}$ after charging to $3.0 \mathrm{~V}$ based on the ex-situ XRD (Figure 3b) and HRTEM (Figure 3c) results. Therefore, the overall electrochemical reactions of $\mathrm{G} / \mathrm{MgH}_{2} @ \mathrm{PTh}$ electrode can be described in the following equations:

$$
\mathrm{MgH}_{2}+2 \mathrm{Li}^{+}+2 \mathrm{e}^{-} \leftrightarrow \mathrm{Mg}+2 \mathrm{LiH}
$$


$17 \mathrm{Mg}+3 \mathrm{Li}^{+}+3 \mathrm{e}^{-} \leftrightarrow \mathrm{Li}_{\mathrm{x}} \mathrm{Mg}(\mathrm{hcp}),(\mathrm{x} \leq 0.15)$

Remarkably, a high discharge capacity of $2846 \mathrm{mAh} \mathrm{g}^{-1}$ was achieved at a current rate of 100 mA g ${ }^{-1}$ for $\mathrm{G} / \mathrm{MgH}_{2} @ \mathrm{PTh}$ in the first cycle (Figure 3d), which is slightly higher than the theoretical capacity of $\mathrm{MgH}_{2}\left(2243 \mathrm{mAh} \mathrm{g}^{-1}\right.$ based on the conversion reaction to form $\mathrm{LiH}$ and the alloying reaction to form hcp-type $\mathrm{Li}_{\mathrm{x}} \mathrm{Mg}$ alloys). It could be mainly attributed to the formation of the SEI layer on the surface and the irreversible side-reactions between the electrode and the electrolyte (Figure S19), as well as the contribution of extra capacity from the possible formation of amorphous bcc-type solid solution of Li-Mg alloys. ${ }^{9}$ Unless otherwise noted, all specific capacities here are calculated based on the weight of $\mathrm{MgH}_{2}$. In addition, the reversible capacity of the first cycle reached $1963 \mathrm{mAh} \mathrm{g}^{-1}$, approaching the theoretical capacity of $\mathrm{MgH}_{2}$. The large irreversible capacity is attributed to the formation of the SEI layer on the surface and the irreversible sidereactions between the electrode and the electrolyte. It should be noted that the performance of G/PTh was also measured under identical test conditions, as shown in Figure S20. It was confirmed that this electrode contributed negligibly to $\mathrm{Li}^{+}$storage $\left(90 \mathrm{mAh} \mathrm{g}^{-1}\right)$. By comparison, the initial discharge and charge capacities of the ball-milled $\mathrm{MgH}_{2}$ particles are only 1000 and $348 \mathrm{mAh} \mathrm{g}^{-1}$, respectively (Figure 3e). Although $\mathrm{G} / \mathrm{MgH}_{2} \mathrm{NCs}$ exhibit better electrochemical performance by taking advantage of nanocrystallization and the presence of graphene (Figure 3e), the initial discharge and charge capacities are only 1647 and $1060 \mathrm{mAh} \mathrm{g}^{-1}$, respectively. It is interesting to note that the corresponding initial Coulombic efficiency (CE) of G/MgH$@ \mathrm{MgTh}_{2}$ reaches 68.9\%, which is much higher than the corresponding values for $\mathrm{MgH}_{2}$ (34.8\%) and $\mathrm{G} / \mathrm{MgH}_{2} \mathrm{NCs}(64.4 \%)$. This finding indicates that the molecular-scale functionality of $\mathrm{MgH}_{2} \mathrm{NCs}$ with PTh membrane could significantly prevent the detrimental and irreversible reactions between $\mathrm{MgH}_{2}$ and the electrolyte. In the second and third cycles, the CE of G/MgH $\mathrm{Mg}_{2} @ \mathrm{PTh}$ dramatically increases to 88\% 
and $91 \%$, respectively, suggesting the rapid stabilization of the SEI layer. After 100 cycles, the reversible capacity is still as high as $1311 \mathrm{mAh} \mathrm{g}^{-1}$, which demonstrates the high reversibility of G/MgH $\mathrm{MgPTh}_{2}$ electrode. On the other hand, the reversible capacity of $\mathrm{MgH}_{2}$ and $\mathrm{G} / \mathrm{MgH}_{2} \mathrm{NCs}$ presents significant degradation down to only 97 and $160 \mathrm{mAh} \mathrm{g}^{-1}$, respectively, which is ascribed to the particle aggregation and/or detachment caused by pulverization due to the large volume expansion during repeated lithiation/delithiation processes, as proved by TEM images of $\mathrm{G} / \mathrm{MgH}_{2}$ NCs after only 20 cycles (Figure S21). SEM images (Figure S22) of the electrodes after 20 cycles of discharge-charge process provide further evidence to the serious aggregation and detachment of $\mathrm{MgH}_{2}$ from graphene in $\mathrm{G} / \mathrm{MgH}_{2} \mathrm{NCs}$, while the homogeneous distribution of $\mathrm{MgH}_{2}$ on graphene is well preserved in $\mathrm{G} / \mathrm{MgH}_{2} @ \mathrm{PTh}$ electrode after the same process. It further confirms that the molecular-scale functionality of $\mathrm{MgH}_{2}$ with $\mathrm{PTh}$ could effectively alleviate the volume change upon cycling electrochemical reaction. Therefore, it is confirmed that the ultra-small particles of $\mathrm{MgH}_{2} \mathrm{NCs}$ and graphene in $\mathrm{G} / \mathrm{MgH}_{2} @ \mathrm{PTh}$ electrode enable the full utilization of $\mathrm{MgH}_{2} \mathrm{NCs}$, leading to high reversible charge-discharge capacity, while the conformal coating of $\mathrm{MgH}_{2} \mathrm{NCs}$ with ultrathin PTh membrane controlled on a molecular level ensures the strong preservation of the nanostructure, leading to significantly improved cycling stability.

The rate capability of the anode materials is a crucial performance indicator for large-scale application of high energy and power density batteries, such as for grid-scale electricity storage and electric vehicle applications. When the current density is increased to $2000 \mathrm{~mA} \mathrm{~g}^{-1}$, the reversible capacity of pure $\mathrm{MgH}_{2}$ and $\mathrm{G} / \mathrm{MgH}_{2} \mathrm{NCs}$ rapidly fades to less than 40 and $360 \mathrm{mAh} \mathrm{g}^{-}$ ${ }^{1}$, respectively, and only a capacity of about $767 \mathrm{mAh} \mathrm{g}^{-1}$ was regained for $\mathrm{G} / \mathrm{MgH}_{2} \mathrm{NCs}$ when the current density was decreased back to $100 \mathrm{~mA} \mathrm{~g}^{-1}$ (Figure 4a). In marked contrast, the $\mathrm{G} / \mathrm{MgH}_{2} @ \mathrm{PTh}$ electrode delivered a high reversible capacity of $1025 \mathrm{mAh} \mathrm{g}^{-1}$ as the current 
density increased to $2000 \mathrm{~mA} \mathrm{~g}^{-1}$. Furthermore, the reversible capacity was restored to $1815 \mathrm{mAh}$ $\mathrm{g}^{-1}$ when the current rate was changed back to $100 \mathrm{~mA} \mathrm{~g}^{-1}$, reaching $97 \%$ of its initial discharge capacity (1868 $\left.\mathrm{mAh} \mathrm{g}^{-1}\right)$, demonstrating its superior reversibility. Most importantly, G/MgH$@$ @PTh electrode exhibited stable cycling performance over 200 charge/discharge cycles at a high current density of 1000 and $2000 \mathrm{~mA} \mathrm{~g}^{-1}$ (Figure 4b). After 200 discharge/charge cycles, a high specific capacity of 926 and $812 \mathrm{mAh} \mathrm{g}^{-1}$, respectively, was obtained, corresponding to capacity retention of 79 and $80 \%$ of the 10 th cycle. The continuous capacity decay is possibly attributable to the deformation of PTh membrane caused by the severe volume changes and the unfavorable reversibility of Li-Mg alloys during cycling. ${ }^{9,}{ }^{35}$ Therefore, when the cut-off voltage was changed to $0.1 \mathrm{~V}$ to avoid the formation of Li-Mg alloys, an exceptional high discharge capacity of $884 \mathrm{mAh} \mathrm{g}^{-1}$ was achieved after 500 cycles, which equals to a capacity retention of $84.5 \%$ of the 10 th cycle. The volumetric capacity is another important metric to consider for many practical applications. Taking the packing density of the $\mathrm{G} / \mathrm{MgH}_{2} @ \mathrm{PTh}$ electrode as approximately $0.9 \mathrm{~g} \mathrm{~cm}^{-3}$, the whole electrode (including graphene, $\mathrm{PTh}$, and $\mathrm{MgH}_{2} \mathrm{NCs}$ ) can deliver volumetric capacities of $422 \mathrm{mAh} \mathrm{cm}^{-3}$ at $2000 \mathrm{~mA} \mathrm{~g}^{-1}$ with the cut-off voltage of $0.1 \mathrm{~V}$. This capacity is comparable to that of the state-of-the-art commercial graphitic anodes (i.e., 500 mAh cm ${ }^{-3}$ ). Additionally, the $\mathrm{CE}$ of $\mathrm{G} / \mathrm{MgH}_{2} @ \mathrm{PTh}$ electrode nearly reaches 100\% throughout the cycling, indicating the excellent cyclability induced by the molecular-scale functionality of $\mathrm{MgH}_{2}$ with ultrathin PTh membrane on graphene in an appropriate voltage window. The increase in the cut-off potential during the lithiation could not only reduce the volume changes, resulting in the improvement of cycle life, but also suppress the formation of lithium dendrites, resulting in enhancement of the battery safety. ${ }^{36}$ 
Electrochemical impedance spectroscopy (EIS) was further performed to understand the effects of homogeneous modification of PTh membrane towards improving the cycling performance of $\mathrm{MgH}_{2}$ electrode (Figure 4c). The high-frequency semicircles correspond to the charge transfer resistance, and the low-frequency oblique lines are typical Warburg behavior, ascribed to $\mathrm{Li}^{+}$ diffusion within the electrode. The charge transfer resistance $\left(R_{\mathrm{ct}}\right)$, which is a key indicator for the kinetics of the electrode, was calculated based on the fitting results (Figure S23a) according to the equivalent circuit model (Figure S23b). Apparently, G/ $\mathrm{MgH}_{2} @ \mathrm{PTh}$ displays an $R_{\text {ct }}$ of $44.4 \Omega$ before cycling, which is lower than that of both the pure $\mathrm{MgH}_{2}(221.8 \Omega)$ and the $\mathrm{G} / \mathrm{MgH}_{2} \mathrm{NCs}$ $(49.3 \Omega)$. This is mainly attributed to the synergistic effects of the highly conductive graphene and the PTh membrane, and the intimate contact between them with electroactive $\mathrm{MgH}_{2} \mathrm{NCs}$, which can facilitate electron transfer from the anchored $\mathrm{MgH}_{2} \mathrm{NCs}$ throughout the whole electrode and thus decrease the resistance. Unfortunately, the corresponding value for $\mathrm{G} / \mathrm{MgH}_{2} \mathrm{NCs}$ increased to $678.9 \Omega$ after 200 cycles due to the formation of a thick, unstable SEI film during cycling, coinciding with large capacity decay. By contrast, the charge transfer resistance exhibits a slight decrease for $\mathrm{G} / \mathrm{MgH}_{2} @ \mathrm{PTh}$ to $35.7 \Omega$, indicating the formation of a stable SEI film and the subsequent activation process during cycling, which provides further evidence of its excellent cycling stability. Moreover, based on the relationship between $Z^{\prime}$ and $\omega^{-1 / 2}$ in the low frequency region (Figure S24), where $\omega$ is the angular frequency, G/MgH$@$ @PTh exhibited lower slopes in comparison with $\mathrm{G} / \mathrm{MgH}_{2} \mathrm{NCs}$ before cycling and after the $200^{\text {th }}$ cycle, suggesting much easier $\mathrm{Li}^{+}$diffusion within the $\mathrm{G} / \mathrm{MgH}_{2} @ \mathrm{PTh}$ electrode. Therefore, the significantly improved electrochemical performance of G/MgH$@$ @PTh in comparison with G/MgH $\mathrm{MCs}_{2}$ could be attributed to the much higher electronic conductivity and the enhanced ionic diffusion kinetics, which were well maintained during the continuous charge-discharge cycling. 
To fully understand the role of the molecular-scale functionality of $\mathrm{MgH}_{2}$ with PTh in the cycling performance of $\mathrm{MgH}_{2}$-based electrode, DFT calculations were further performed to examine the interaction between the electroactive species and the PTh membrane. The optimized result from the calculation (Figure S25) of the binding energy between $\mathrm{MgH}_{2}$ and $\mathrm{PTh}$ was 0.46 $\mathrm{eV}$, much higher than for $\mathrm{MgH}_{2}$-graphene system $(0.3 \mathrm{eV})$, which reveals the favorable molecular interaction between $\mathrm{MgH}_{2}$ and PTh, and could enable the ultrathin PTh membrane to constrain electroactive $\mathrm{MgH}_{2} \mathrm{NCs}$ during cycling. Moreover, it should be noted that $\mathrm{LiH}$ and $\mathrm{Mg}$, the discharge products of G/MgH$@ \mathrm{MPTh}_{2}$ electrode, also exhibit strong molecular interaction with PTh, exhibiting a binding energy of $0.57 \mathrm{eV}$ and $0.16 \mathrm{eV}$, respectively. Therefore, the theoretical calculations provide evidence for the enhancement of affinity between PTh and $\mathrm{MgH}_{2}$, as well as the discharged products of G/MgH $@$ @PTh electrode, through uniform molecular interaction, which could significantly improve the structural integrity. Consequently, G/MgH @@PTh still maintained its original appearance (Figure S20), even after the anode was charged-discharged over 500 cycles, implying the formation of stable SEI layers. Only few particles, however, could be observed in $\mathrm{G} / \mathrm{MgH}_{2} \mathrm{NCs}$ after only 50 cycles. The particle size distribution exhibits that the average particle size of $\mathrm{MgH}_{2} \mathrm{NCs}$ is around $17.9 \mathrm{~nm}$ after cycling (Figure S26) with only limited increase compared to that before cycling, which corresponds well with the long cycle life of G/MgH $\mathrm{Mg}_{2} @ \mathrm{PTh}$ and its high coulombic efficiency. In addition, the carbon, magnesium, and sulfur element mapping (Figure 4d) verifies that the homogeneous distribution of $\mathrm{MgH}_{2} \mathrm{NCs}$ in $\mathrm{G} / \mathrm{MgH}_{2} @ \mathrm{PTh}$ electrode is well preserved after cycling, which visually demonstrates the synergistic effects of both the chemical affinity and the intimate physical contact between $\mathrm{MgH}_{2}$, as well as its discharge products, and the PTh membrane in suppressing the aggregation of electroactive nanoparticles during repeated lithiation and delithiation. As a result, no obvious aggregation could be observed 
on the relatively smooth surface of the electrode with the homogenous distribution of $\mathrm{Mg}, \mathrm{S}$, and $\mathrm{C}$ in the electrode (Figure S27).

It could be noted that the electrochemical properties of $\mathrm{G} / \mathrm{MgH}_{2} @ \mathrm{PTh}$ electrode are comparable to or even much better than the state-of-art values for typical metal-based compounds, including transition metal oxides (phosphides and/or nitrides), metal sulfides, and alloy-based metals (e.g., Ge and Sn), in terms of specific capacity, cyclability, and rate capability (Figure 4e, Table S1). ${ }^{29-}$ ${ }^{34}$ Such superior performance can be ascribed to the following advantages: First, the self-initiated, selective, and self-limiting polymerization of thiophene monomer induced by $\mathrm{Mg} \mathrm{NCs}$, as well as the favorable molecular interaction between them, ensures the uniform and conformal coating of the $\mathrm{MgH}_{2} \mathrm{NCs}$ by conductive PTh nanofilms. Second, ultra-small $\mathrm{MgH}_{2} \mathrm{NCs}$ significantly enhance the utilization rate of electroactive materials and tolerate the absolute strain and stress during $\mathrm{Li}^{+}$insertion and extraction processes. Moreover, the uniform dispersion of $\mathrm{MgH}_{2}$ nanograins on graphene, coupled with the conformal coating of ultrathin PTh membrane, can effectively accommodate the large volume variations and inhibit particle aggregation over repeated lithiation/delithiation processes. Most importantly, the strong molecular interaction and the intimate physical contact between the ultrathin PTh membrane and the $\mathrm{MgH}_{2}$ inside and its charge/discharge products involved in the electrochemical reactions effectively prevent detrimental reactions and promote the formation of stable SEI films, preserving the structural integrity of the electrodes over lithiation/delithiation processes during cycling, and, coupled with the homogeneous distribution of graphene in the electrode, providing fast charge and $\mathrm{Li}^{+}$transfer pathways. Finally, the cross-linked structure with stacked graphene enclosing $\mathrm{MgH}_{2} @ \mathrm{PTh}$ coreshell NPs inside forms a 3D conductive and mechanically robust network, so that the usage of 
conductive carbon and binder is avoided, which further facilitates the electron transport, $\mathrm{Li}^{+}$ diffusion kinetics, and stable reversibility over extended cycling.

\section{CONCLUSION}

In conclusion, molecular-scale functionality of metal hydride NPs with conductive polymer on graphene has been achieved successfully via a self-initiated polymerization method, leading to the formation of ultra-small $\mathrm{MgH}_{2} @ \mathrm{PTh}$ core-shell NPs uniformly distributed on graphene. The combination of ultrafine $\mathrm{MgH}_{2} \mathrm{NCs}$, highly conductive graphene, and ultrathin PTh membrane synergistically improves the ion and charge transfer kinetics of $\mathrm{MgH}_{2}$ anode. More importantly, the favorable chemical interaction and intimate contact between $\mathrm{MgH}_{2} \mathrm{NCs}$, as well as the various products involved in the electrochemical reactions, and the PTh nanofilms effectively prevent detrimental reactions and improve the structural integrity during charge-discharge processes, leading to significantly improved rate performance, reversible capacity, and cycling stability. Therefore, this work presents an effective route towards developing high-capacity metal-hydridebased anodes for LIBs and pushes forward their promising practical applications. We believe that the thus-developed self-initiated polymerization route for the molecular-scale functionality of nanoparticles and/or nanostructures may be of high interest for many other applications.

\section{EXPERIMENTAL METHODS}

Synthesis of $\mathbf{G} / \mathbf{M g H}_{2} \mathbf{~ N C s}$. G/MgH $\mathrm{MCs}_{2}$ were synthesized via the facile hydrogenation of di$n$-butylmagnesium $\left(\mathrm{MgBu}_{2}\right)$ in cyclohexane. Typically, $1.6 \mathrm{~mL} \mathrm{MgBu} 2$ solution (1 $\mathrm{M}$ in heptane) and $0.0248 \mathrm{~g}$ graphene were uniformly mixed in cyclohexane $(40 \mathrm{~mL})$ in a pressure reactor vessel. The hydrogenation reaction of $\mathrm{MgBu}_{2}$ was then performed at $190{ }^{\circ} \mathrm{C}$ under 35 atm $\mathrm{H}_{2}$ for $24 \mathrm{~h}$. 
Finally, the solution was centrifuged and vacuum-dried at $100{ }^{\circ} \mathrm{C}$ under dynamic vacuum on a Schlenk line, which leads to the formation of $\mathrm{G} / \mathrm{MgH}_{2} \mathrm{NCs}$.

Synthesis of G/Mg@PTh. G/Mg NCs were firstly fabricated via thermal annealing of G/MgH NCs at $300{ }^{\circ} \mathrm{C}$ for complete dehydrogenation. In a typical process to synthesize $\mathrm{G} / \mathrm{Mg} @ \mathrm{PTh}$, a dry round-bottomed flask was loaded with $200 \mathrm{mg} \mathrm{G} / \mathrm{Mg} \mathrm{NCs}$ and $20 \mathrm{ml}$ tetrahydrofuran (THF), followed by uniform dispersion using ultrasonication for $0.5 \mathrm{~h}$ under argon. Subsequently, 60.24 mg 2,5-dibromothiophene $\left(\mathrm{C}_{4} \mathrm{H}_{2} \mathrm{Br}_{2} \mathrm{~S}\right)$ dissolved in $10 \mathrm{~mL}$ THF was added dropwise, and the mixture was then heated to reflux for around $2 \mathrm{~h}$ to achieve uniform adsorption of thiophene monomer on $\mathrm{Mg} \mathrm{NCs}$. After further ultrasonication for $0.5 \mathrm{~h}, 0.26 \mathrm{mg}$ nickel(II) 2,4pentanedionate in $3 \mathrm{ml} \mathrm{THF}$ was supplied as the catalyst, and vigorously stirred for $6 \mathrm{~h}$ at $65^{\circ} \mathrm{C}$. Finally, the solution was centrifuged and washed with anhydrous THF three times, and G/Mg@PTh was obtained after the removal of the solvent under dynamic vacuum for $24 \mathrm{~h}$ at 70 ${ }^{\circ} \mathrm{C}$.

Synthesis of G/MgH2@PTh. G/MgH $\mathrm{Mg}_{2} @ \mathrm{PTh}$ was synthesized by the thermal treatment of $\mathrm{G} / \mathrm{Mg} @ \mathrm{PTh}$ on a Sieverts apparatus under a hydrogen pressure of 100 atm at $150{ }^{\circ} \mathrm{C}$ for $10 \mathrm{~h}$.

Characterizations. The crystal structure of G/MgH$@$ PTh electrode was characterized by powder X-ray diffraction (XRD, D8 Advance, Bruker AXS) with $\mathrm{Cu} \mathrm{K} \alpha$ radiation. In order to prevent any possible chemical reactions between air and the sample during the XRD measurement, amorphous tapes were used to cover samples. Raman spectroscopy was performed on a NEXUS 670 Fourier-transform infrared (FT-IR) Raman spectrometer. The morphology of the samples was revealed by field emission scanning electron microscopy (FE-SEM, JEOL 7500FA, Tokyo, Japan) and transmission electron microscopy (TEM, JEOL 2011 F, Tokyo, Japan). Nitrogen 
absorption/desorption isotherms at the temperature of liquid nitrogen were obtained using a Quantachrome NOVA 4200e instrument to characterize the porous structure of the samples. The pore volumes and pore size distributions were calculated from the adsorption branches of the isotherms according to the Barrett-Joyner-Halenda $(\mathrm{BJH})$ model. X-ray photoelectron spectra (XPS) was obtained on a Perkin Elmer PHI 5000C ESCA system coupled with a dual X-ray source, for which an $\mathrm{Mg} \mathrm{K} \alpha(1253.6 \mathrm{eV})$ anode was adopted with a hemispherical energy analyzer. The background pressure was preserved below $10^{-6} \mathrm{~Pa}$ during data acquisition, and measurements were conducted at a pass energy of $93.90 \mathrm{eV}$. All binding energies were calibrated using contaminant carbon $(\mathrm{C} 1 \mathrm{~s}=284.6 \mathrm{eV})$. The hydrogen absorption properties of the as-synthesized G/Mg@PTh were investigated on a Sieverts apparatus, denoted as a gas reaction controller (GRC, Advanced Materials Corp., USA). The hydrogen absorption kinetics data were collected at $150{ }^{\circ} \mathrm{C}$ with an initial hydrogen pressure of $100 \mathrm{~atm}$. The hydrolysis reaction in sulphuric acid was further performed to verify the amount of $\mathrm{MgH}_{2}$ in the as-prepared G/MgH $@ \mathrm{PTh}$ composite from the hydrogenation of $\mathrm{G} / \mathrm{Mg} / \mathrm{PTh}$. In a typical measurement, $10 \mathrm{~mL}$ water was loaded into a $50 \mathrm{~mL}$ flask containing 100 mg G/MgH $@$ PTh composite under mechanical stirring, followed by the introduction of $4 \mathrm{~mL} \mathrm{H}_{2} \mathrm{SO}_{4}(1 \mathrm{M})$ solution by 4 identical portions every minute. A desiccator composed of $\mathrm{NaOH}-\mathrm{CaO}$ was used to remove the water vapor and possible acid gas from the generated hydrogen. Finally, the amount of hydrogen was quantified by water displacement in an inverted graduated cylinder over a water-filled tank.

\section{ASSOCIATED CONTENT}

\section{Supporting Information.}

The following files are available free of charge. 
Details of electrochemical measurements and theoretical calculations, XRD, XPS, and Raman results of the as-synthesized samples.

\section{AUTHOR INFORMATION}

\section{Corresponding Author}

*E-mail: yuxuebin@fudan.edu.cn.

*E-mail: yangzz@iccas.ac.cn.

\section{Author Contributions}

\#These authors contributed equally.

\section{ACKNOWLEDGMENT}

This work was partially supported by the National Science Fund for Distinguished Young Scholars (51625102), the National Natural Science Foundation of China (51471053), and the Science and Technology Commission of Shanghai Municipality (17XD1400700). The authors also would like to thank Dr. Tania Silver for critical reading of the manuscript.

\section{REFERENCES}

(1) Dunn B.; Kamath H.; Tarascon J. M. Electrical Energy Storage for the Grid: A Battery of Choices. Science 2011, 334, 928-935.

(2) Bruce P. G.; Scrosati B.; Tarascon J. M. Nanomaterials for Rechargeable Lithium Batteries. Angew. Chem. Int. Ed. 2008, 47, 2930-2946.

(3) Dudney N.J.; Li J. Using All Energy in a Battery. Science 2015, 347, 131. 
(4) Sun Y.; Liu N.; Cui Y. Promises and Challenges of Nanomaterials for Lithium-Based Rechargeable Batteries. Nat. Energy 2016, 1, 16071.

(5) Choi N. S.; Chen Z. H.; Freunberger S. A.; Ji, X. L.; Sun Y. K.; Amine K.; Yushin G.; Nazar L. F.; Cho J.; Bruce P. G. Challenges Facing Lithium Batteries and Electrical Double-Layer Capacitors. Angew. Chem. Int. Ed. 2012, 51, 9994-10024.

(6) Tang Y.; Zhang Y.; Li W.; Ma B.; Chen X. Rational Material Design for Ultrafast Rechargeable Lithium-Ion Batteries. Chem. Soc. Rev. 2015, 44, 5926-5940.

(7) Lee K.T.; Cho J. Roles of Nanosize in Lithium Reactive Nanomaterials for Lithium Ion Batteries. Nano Today 2011, 6, 28-41.

(8) Manthiram A.; Fu Y.; Su Y. S. In Charge of the World: Electrochemical Energy Storage. $J$. Phys. Chem. Lett. 2013, 4, 1295-1297.

(9) Oumellal Y.; Rougier A.; Nazri G. A.; Tarascon J. M.; Aymard L. Metal Hydrides for LithiumIon Batteries. Nat. Mater. 2008, 7, 916-921.

(10) Aymard L.; Oumellal Y.; Bonnet J. P. Metal Hydrides: An Innovative and Challenging Conversion Reaction Anode for Lithium-Ion Batteries. Beilstein J. Nanotechnol. 2015, 6, 18211839.

(11) Huang L.; Aymard L.; Bonnet J. P. $\mathrm{MgH}_{2}-\mathrm{TiH}_{2}$ Mixture as an Anode for Lithium-Ion Batteries: Synergic Enhancement of the Conversion Electrode Electrochemical Performance. J. Mater. Chem. A 2015, 3, 15091-15096. 
(12) Oumellal Y.; Zlotea C.; Bastide S.; Cachet-Vivier C.; Leonel E.; Sengmany S.; Leroy E.; Aymard L.; Bonnet J. P.; Latroche M. Bottom-Up Preparation of $\mathrm{MgH}_{2}$ Nanoparticles with Enhanced Cycle Life Stability During Electrochemical Conversion in Li-Ion Batteries. Nanoscale 2014, 6, 14459-14466.

(13) Zeng L.; Kawahito K.; Ikeda S.; Ichikawa T.; Miyaoka H.; Kojima Y. Metal Hydride-Based Materials Towards High Performance Negative Electrodes for All-Solid-State Lithium-Ion Batteries. Chem. Commun. 2015, 51, 9773-9776.

(14) Tan G. Q.; Wu F.; Yuan Y. F.; Chen R. J.; Zhao T.; Yao Y.; Qian J.; Liu J. R.; Ye Y. S.; Yassar R. S.; Lu J.; Amine K. Freestanding Three-Dimensional Core-Shell Nanoarrays for Lithium-Ion Battery Anodes. Nat. Commun. 2016, 7, 11774.

(15) Yu X. Y.; Yu L.; Lou X. W. Metal Sulfide Hollow Nanostructures for Electrochemical Energy Storage. Adv. Energy Mater. 2016, 6, 1501333.

(16) Wu H. B.; Zhang G.; Yu L.; Lou X. W. One-Dimensional Metal Oxide-Carbon Hybrid Nanostructures for Electrochemical Energy Storage. Nanoscale Horiz. 2016, 1, 27-40.

(17) Liu N.; Lu Z. D.; Zhao J.; McDowell M. T.; Lee H. W.; Zhao W. T.; Cui Y. A PomegranateInspired Nanoscale Design for Large-Volume-Change Lithium Battery Anodes. Nat. Nano. 2014, 9, 187-192.

(18) Zhu Y.; Fan X.; Suo L.; Luo C.; Gao T.; Wang C. Electrospun FeS2@Carbon Fiber Electrode as a High Energy Density Cathode for Rechargeable Lithium Batteries. ACS Nano 2016, 10, 15291538. 
(19) Myung S. T.; Noh H. J.; Yoon S. J.; Lee E. J.; Sun Y. K. Progress in High-Capacity CoreShell Cathode Materials for Rechargeable Lithium Batteries. J. Phys. Chem. Lett., 2014, 5, 671679.

(20) Schüch F. Encapsulation Strategies in Energy Conversion Materials. Chem. Mater., 2014, 26, 423-434.

(21) Feng H. P.; Tang L.; Zeng G. M.; Tang J.; Deng Y. C.; Tan M.; Liu Y. N.; Zhou Y. Y.; Ren X. Y.; Chen S. Carbon-Based Core-Shell Nanostructured Materials for Electrochemical Energy Storage. J. Mater. Chem. A, 2018, 6, 7310-7337.

(22) Roy P.; Srivastava S. K. Nanostructured Anode Materials for Lithium Ion Batteries. J. Mater. Chem. A, 2015, 3, 2454-2484.

(23) Zhang Q. F.; Uchaker E.; Candelaria S. L.; Cao G. Z. Nanomaterials for Energy Conversion and Storage. Chem. Soc. Rev. 2013,42, 3127-3171.

(24) Zhou W. W.; Zhu J. X.; Cheng C. W.; Liu J. P.; Yang H. P.; Cong C. X.; Guan C.; Jia X. T.; Fan H. J.; Yan Q. Y.; Li C. M.; Yu T. A General Strategy toward Graphene@Metal Oxide CoreShell Nanostructures for High-Performance Lithium Storage. Energy Environ. Sci., 2011,4, 49544961.

(25) Liu J.; Xu X. J.; Hu R. Z.; Yang L. C.; Zhu M.; Uniform Hierarchical Fe ${ }_{3} \mathrm{O}_{4} @$ Polypyrrole Nanocages for Superior Lithium Ion Battery Anode. Adv. Energy Mater. 2016, 6, 1600256. 
(26) Mao M.; Yan F.; Cui C.; Ma J.; Zhang M.; Wang T.; Wang C. S. "Pipe-Wire TiO2Sn@Carbon Nanofibers Paper Anodes for Lithium and Sodium Ion Batteries", Nano Lett. 2017, $17,3830-3836$.

(27) Zhang B. P.; Xia G. L.; Sun D. L.; Fang F.; Yu X. B. Magnesium Hydride Nanoparticles SelfAssembled on Graphene as Anode Material for High-Performance Lithium-Ion Batteries. ACS Nano 2018, 12, 3816-3824.

(28) Wang H.; Dai H. Strongly Coupled Inorganic-Nano-Carbon Hybrid Materials for Energy Storage. Chem. Soc. Rev. 2013, 42, 3088-3113.

(29) Wu S. P.; Xu R.; Lu M. J.; Ge R. Y.; Locozzia J.; Han C. P.; Jiang B. B.; Lin Z. Q. GrapheneContaining Nanomaterials for Lithium-Ion Batteries. Adv. Energy Mater. 2015, 5, 1500400.

(30) Xia G. L.; Tan Y. B.; Chen X. W.; Sun D. L.; Guo Z. P.; Liu H. K.; Ouyang L. Z.; Zhu M.; Yu X. B. Monodisperse Magnesium Hydride Nanoparticles Uniformly Self-Assembled on Graphene. Adv. Mater. 2015, 27, 5981-5988.

(31) Yamamoto T.; Sanechika K.; Yamamoto A. Preparation of Thermostable and ElectricConducting Poly(2,5-thienylene). J. Polym. Sci., Polym. Lett. Ed. 1980, 18, 9-12.

(32) Han M. G.; Foulger S. H. Crystalline Colloidal Arrays Composed of Poly(3,4ethylenedioxythiophene)-Coated Polystyrene Particles with a Stop Band in the Visible Regime. Adv. Mater. 2004, 16, 231-234. 
(33) Matović L.; Novakovic N.; Kurko S.; Siljegoic M.; Matovic B.; Popovic Z. K.; Romcevic N.; Ivanovic N.; Novakovic J. G. Structural Destabilisation of $\mathrm{MgH}_{2}$ Obtained by Heavy Ion Irradiation. Int. J. Hydrogen Energy 2009, 34, 7275-7282.

(34) Zhang S.; Zhu L.; Song H.; Chen X.; Zhou J. Enhanced Electrochemical Performance of MnO Nanowire/Graphene Composite During Cycling as the Anode Material for Lithium-Ion Batteries. Nano Energy 2014, 10, 172-180.

(35) Brutti S.; Mulas G.; Piciollo E.; Panero S.; Reale P. Magnesium Hydride as a High Capacity Negative Electrode for Lithium Ion Batteries. J. Mater. Chem. 2012, 22, 14531-14537.

(36) Lin L.; Xu X.; Chu C.; Majeed M. K.; Yang J. Mesoporous Amorphous Silicon: A Simple Synthesis of a High-Rate and Long-Life Anode Material for Lithium-Ion Batteries. Angew. Chem. Int. Ed. 2016, 55, 14063-14066.

(37) Cao K. Z.; Jiao L. F.; Liu H. Q.; Liu Y. C.; Wang Y. J.; Guo Z. P.; Yuan H. T. 3D Hierarchical Porous $\alpha-\mathrm{Fe}_{2} \mathrm{O}_{3}$ Nanosheets for High-Performance Lithium-Ion Batteries. Adv. Energy Mater. 2015, 5, 1401421.

(38) Zhou X.; Yu L.; Lou X. W. Formation of Uniform N-Doped Carbon-Coated $\mathrm{SnO}_{2}$ Submicroboxes with Enhanced Lithium Storage Properties. Adv. Energy Mater. 2016, 6, 1600451.

(39) Zhang W.; Chu X. Q.; Chen C. J.; Xiang J. W.; Liu X. X.; Huang Y. H.; Hu X. L. Rational Synthesis of Carbon-Coated Hollow Ge Nanocrystals with Enhanced Lithium-Storage Properties. Nanoscale 2016, 8, 12215-12220. 
(40) Yu S. H.; Lee D. J.; Park M.; Kwon S. G.; Lee H. S.; Jin A. H.; Lee K. S.; Lee J. E.; Oh M. H.; Kang K.; Sung Y. E.; Hyeon T. Hybrid Cellular Nanosheets for High-Performance LithiumIon Battery Anodes. J. Am. Chem. Soc. 2015, 137, 11954-11961.

(41) Zhao D.; Cui Z.; Wang S.; Qin J.; Cao M. VN Hollow Spheres Assembled from Porous Nanosheets for High-Performance Lithium Storage and the Oxygen Reduction Reaction. J. Mater. Chem. A 2016, 4, 7914-7923.

(42) Zhang Y.; Zhang H.; Feng Y.; Liu L.; Wang Y. Unique $\mathrm{Fe}_{2} \mathrm{P}$ Nanoparticles Enveloped in Sandwichlike Graphited Carbon Sheets as Excellent Hydrogen Evolution Reaction Catalyst and Lithium-Ion Battery Anode. ACS Appl. Mater. Interfaces 2015, 7, 26684-26690. 
FIGURES
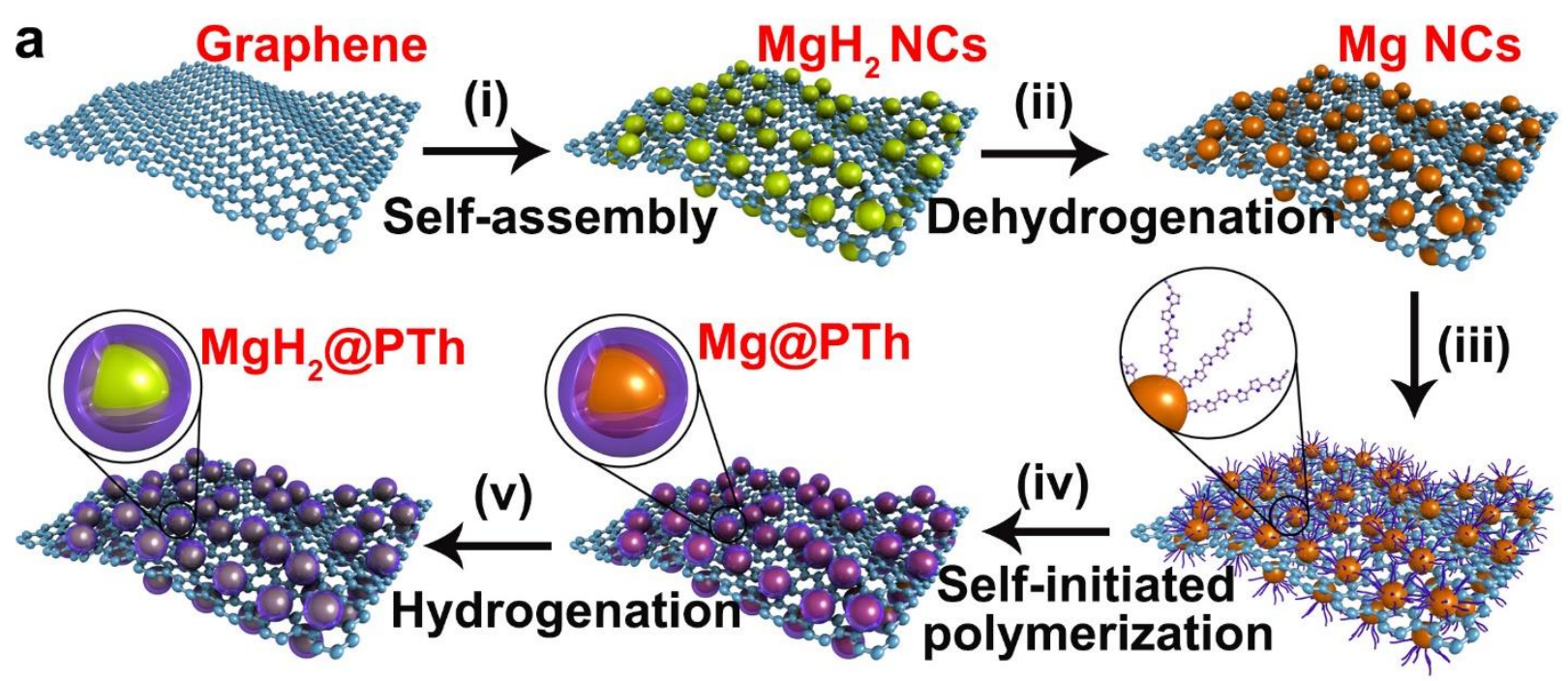
(i) $\left(\mathrm{C}_{4} \mathrm{H}_{9}\right)_{2} \mathrm{Mg}+2 \mathrm{H}_{2} \rightarrow \mathrm{MgH}_{2}+\mathrm{C}_{4} \mathrm{H}_{10}$
(ii) $\mathrm{MgH}_{2} \rightarrow \mathrm{Mg}+\mathrm{H}_{2}$
(iii, iv) $\mathrm{Mg}+\mathrm{C}_{4} \mathrm{H}_{2} \mathrm{SBr}_{2} \rightarrow \mathrm{MgBr}_{2}+\mathrm{PTh}$
(v) $\mathrm{Mg}+\mathrm{H}_{2} \rightarrow \mathrm{MgH}_{2}$
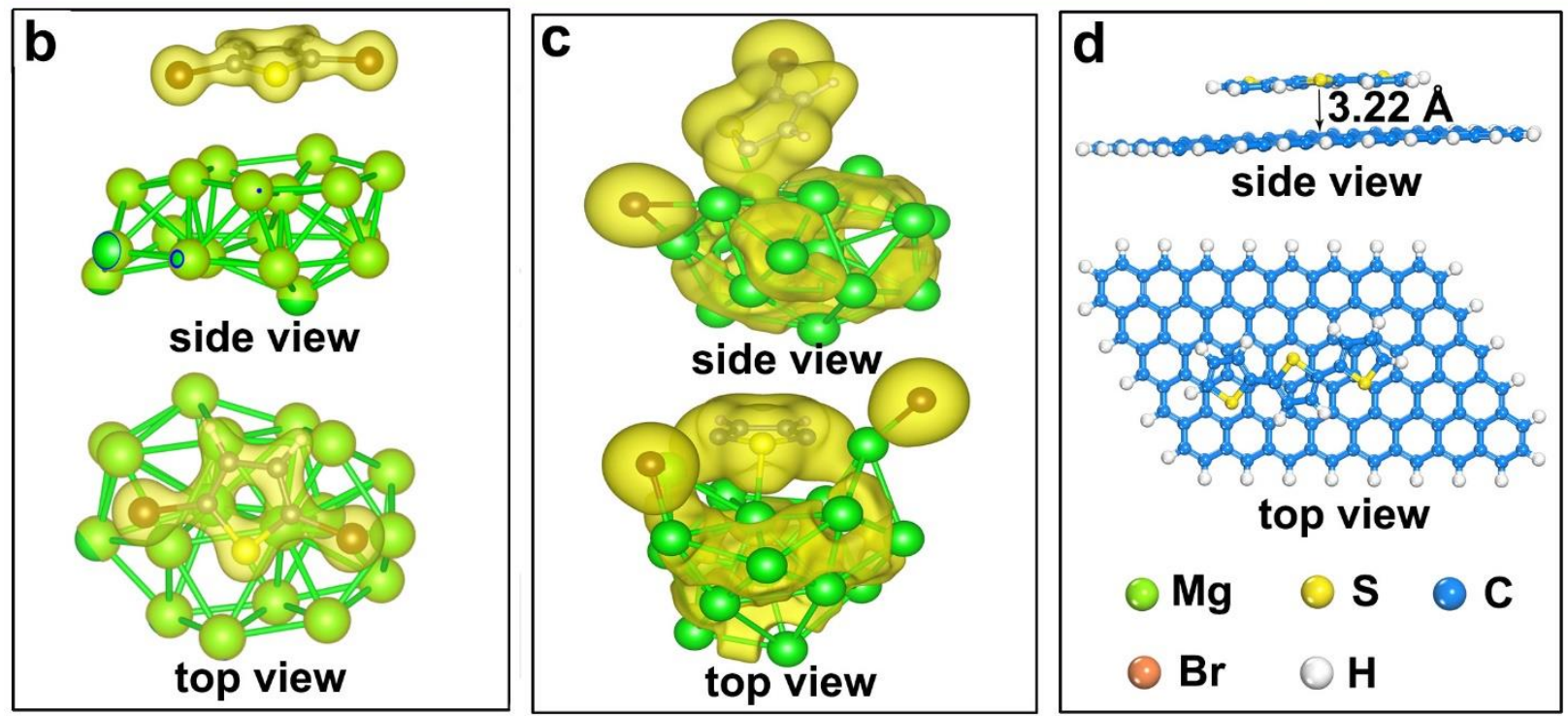

Figure 1. (a) Schematic illustration of the formation of G/MgH $@$ PTh. Structures of the most stable binding configurations from DFT calculations after full relaxation of $\mathrm{C}_{4} \mathrm{H}_{2} \mathrm{SBr}_{2}$ on pure $\mathrm{Mg}_{18}$ clusters (b) and $\mathrm{C}_{4} \mathrm{H}_{2} \mathrm{SMgBr}$ on pure $\mathrm{Mg}_{17}$ clusters (c). Charge density isosurfaces are shown. 
(d) Atomic structures (top and side views) for the adsorption of PTh on graphene in the most stable configuration.
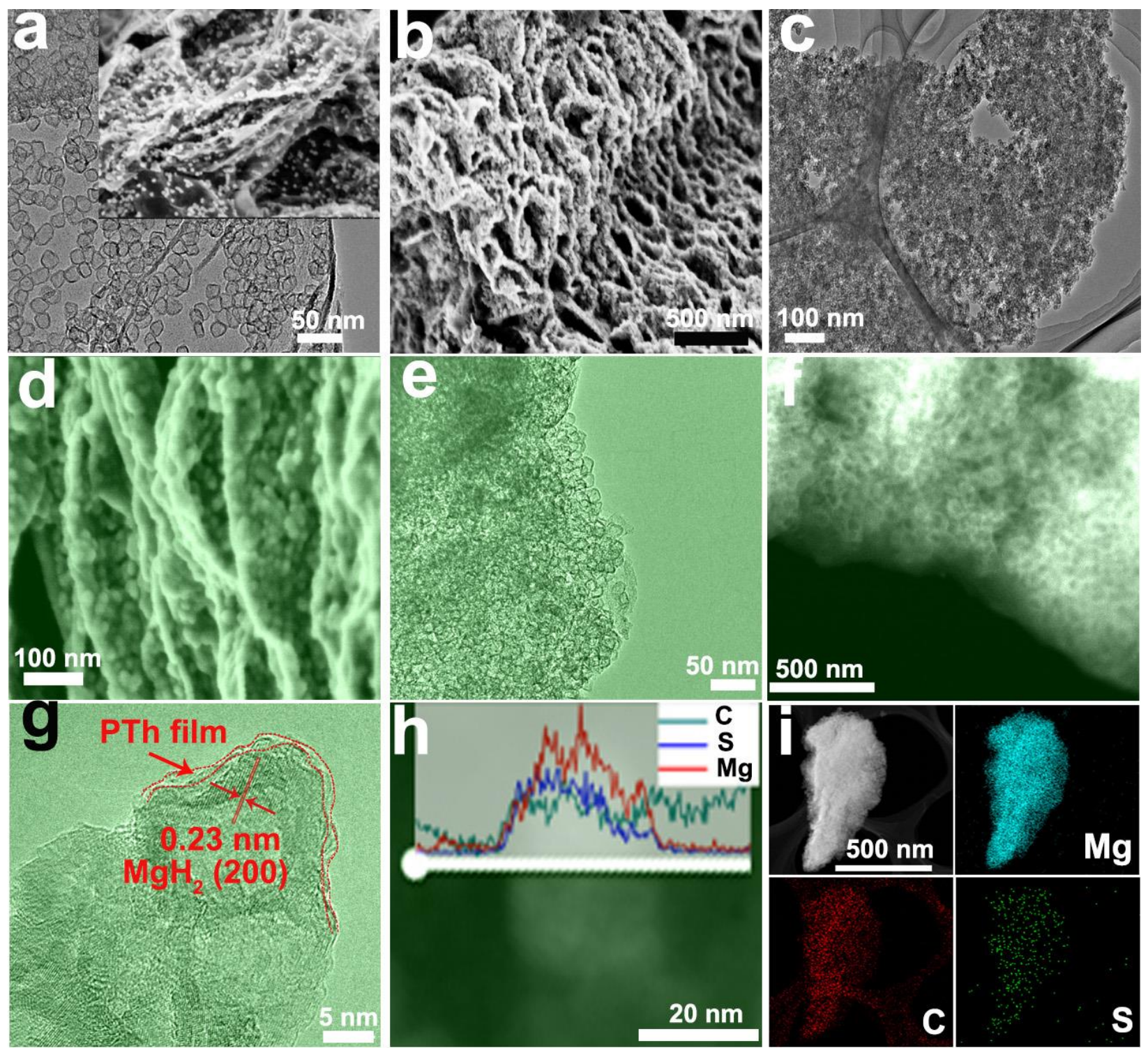

Figure 2. (a) TEM image of $\mathrm{G} / \mathrm{MgH}_{2} \mathrm{NCs}$. The inset shows the corresponding SEM image. (b) SEM and (c) TEM images of G/Mg@PTh. (d) SEM, (e) TEM, (f) HRTEM, and (g) STEM images of G/MgH $\mathrm{MgPTh}_{2} @$ (h) EDS line scan (route marked by white line) of G/MgH $\mathrm{M}_{2} @ \mathrm{PTh}$ on an STEM image. The inset shows the corresponding element distributions of carbon, magnesium, and sulfur, respectively. (i) Elemental mapping of G/MgH$@ \mathrm{Mg}_{2}$ PTh. 

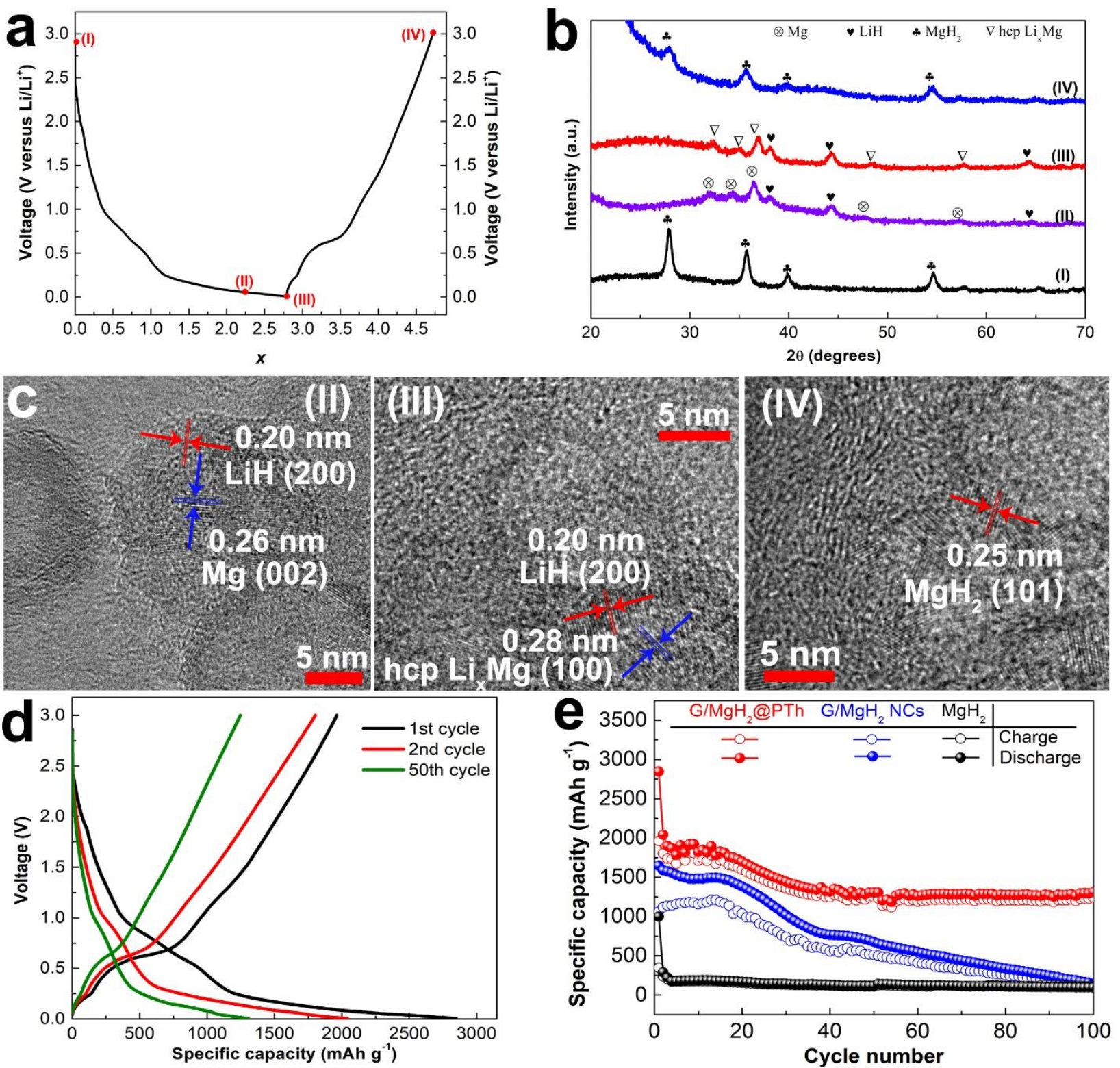

Figure 3. (a) Evolution of the potential $(V)$ as a function of $x(x=$ lithium mole fraction) for the $\mathrm{G} / \mathrm{MgH}_{2} @ \mathrm{PTh}$ electrode at $100 \mathrm{~mA} \mathrm{~g}^{-1}$ in the first cycle. (b) Ex-situ XRD patterns of G/MgH $\mathrm{Mg}_{2} @ \mathrm{PTh}$ electrode collected at the selected charged/discharged states. (c) HRTEM images of $\mathrm{G} / \mathrm{MgH}_{2} @ \mathrm{PTh}$ electrode at the selected charged/discharged states. (d) Charge and discharge curves of the G/MgH$@ \mathrm{MPTh}_{2}$ electrode at $100 \mathrm{~mA} \mathrm{~g}^{-1}$ in the $1^{\text {st }}, 2^{\text {nd }}$, and $50^{\text {th }}$ cycles. (e) Cycling 
performance of G/MgH $@$ @PTh electrode at 100 mA g ${ }^{-1}$ compared with G/MgH $\mathrm{MCs}_{2}$ and $\mathrm{MgH}_{2}$ particles.
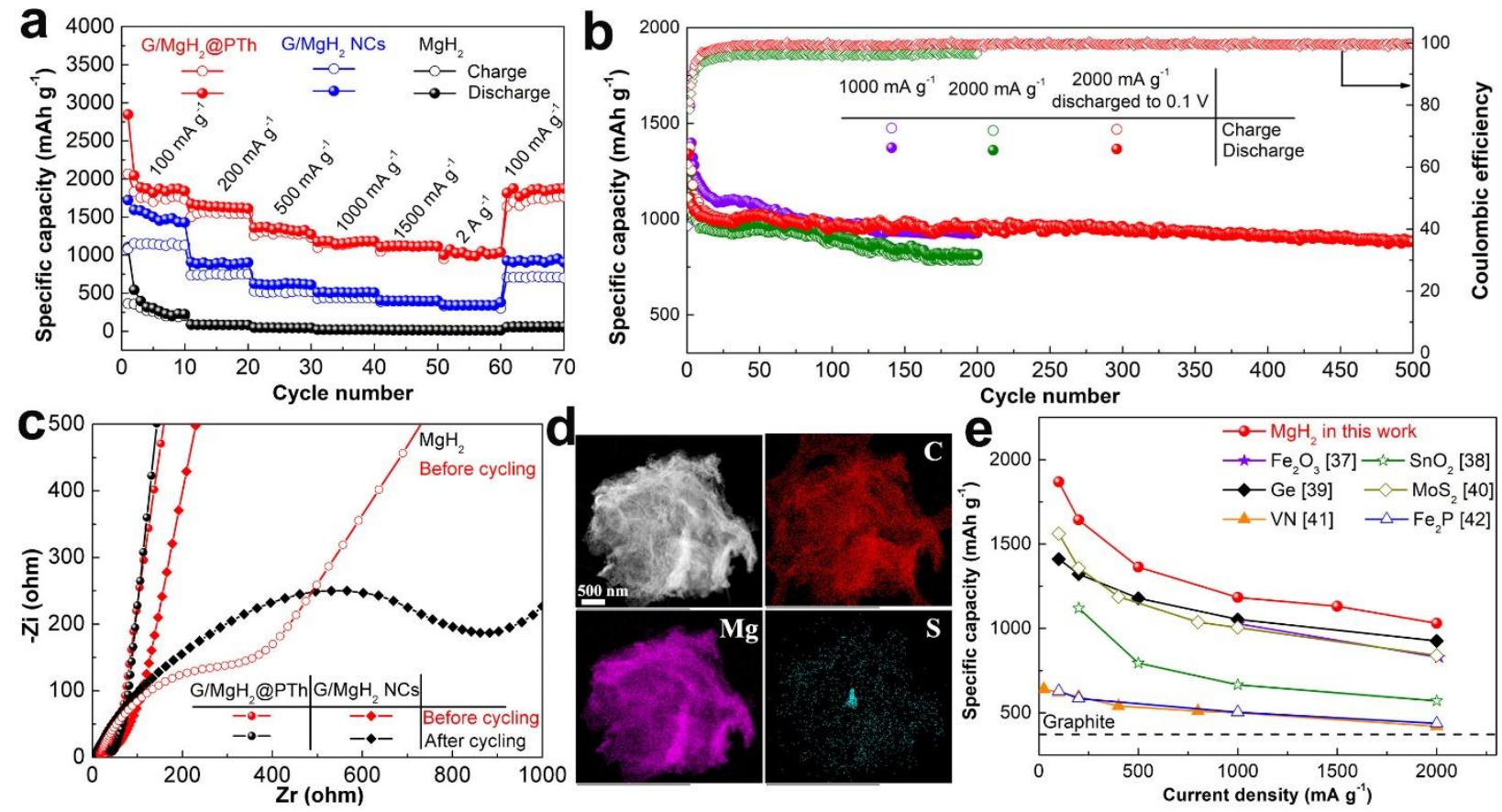

Figure 4. (a) Rate performance of $\mathrm{G} / \mathrm{MgH}_{2} @ \mathrm{PTh}, \mathrm{G} / \mathrm{MgH}_{2} \mathrm{NCs}$, and pure $\mathrm{MgH}_{2}$ at various current densities. (b) Cycling performance of $\mathrm{G} / \mathrm{MgH}_{2} @ \mathrm{PTh}$ and Coulombic efficiency at current densities of 1000 and $2000 \mathrm{~mA} \mathrm{~g}^{-1}$ in the voltage window of 0.001-3.0 V, and of G/MgH2@PTh at $2000 \mathrm{~mA} \mathrm{~g}^{-1}$ in the voltage window of 0.1-3.0 V. (c) Nyquist plots of G/MgH $@$ PTh and $\mathrm{G} / \mathrm{MgH}_{2} \mathrm{NCs}$ electrodes in the discharged state before cycling and after 200 cycles. (d) STEM image and the corresponding elemental mapping of $\mathrm{G} / \mathrm{MgH}_{2} @ \mathrm{PTh}$ after 500 cycles. (e) Comparison of rate performance between $\mathrm{G} / \mathrm{MgH}_{2} @ \mathrm{PTh}$ electrode and the recently reported values for typical metal-based anode materials, including the theoretical values of graphite for comparison. The specific capacity is calculated based on the weight of electroactive materials in the composite, assuming that the capacity contribution of other matrix in the composites is negligible. 


\section{Table of Contents}

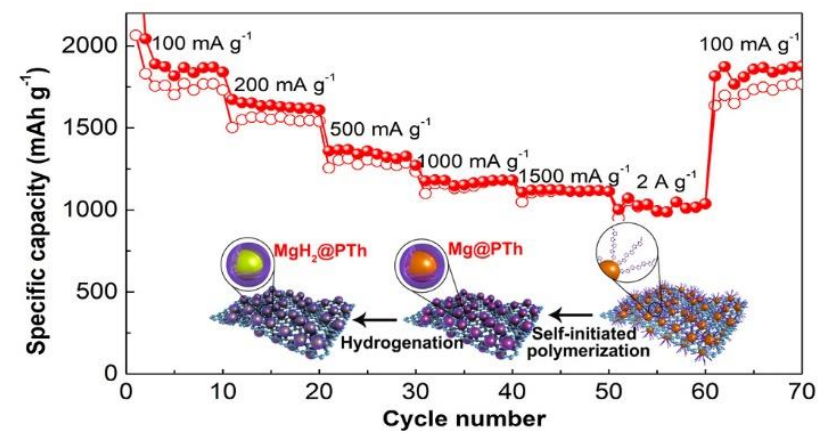

